\title{
MIGRAÇÃO SUL-SUL
}

\begin{tabular}{ll} 
Título & $\begin{array}{l}\text { Nuevos destinos de la migración africana reciente: los } \\
\text { senegaleses en Argentina }\end{array}$ \\
Autor/es & $\begin{array}{l}\text { Bernarda Zubrzycki } \\
\text { Con este trabajo pretendemos aportar al conocimiento } \\
\text { de un nuevo fenómeno vinculado a la movilidad humana: } \\
\text { las migraciones africanas subsaharianas hacia Sudamérica } \\
\text { en general, y migraciones senegalesas hacia Argentina en } \\
\text { particular. Nos centraremos en caracterizar la migración } \\
\text { senegalesa hacia Argentina, las motivaciones para migrar y las } \\
\text { formas de ingresar al país. }\end{array}$ \\
Ano/Edição & $\begin{array}{l}\text { Ano XXVI, no 72, jan-jun/2013. São Paulo } \\
\text { Título }\end{array}$ \\
Autor/es & $\begin{array}{l}\text { Novas rotas da migração Sul-Sul: o caso dos peruanos no } \\
\text { Brasil }\end{array}$ \\
Resumo & $\begin{array}{l}\text { Camila Daniel } \\
\text { Este artigo tem como objetivo refletir sobre a dinâmica } \\
\text { de mobilidade dos peruanos para o Brasil. Analisando seu } \\
\text { perfil e as principais motivações que os impulsionam a ir } \\
\text { para o exterior, indica-se que, ao contrário do que o senso } \\
\text { comum imagina, a população peruana no Brasil é diversa e } \\
\text { heterogênea, incluindo desde trabalhadores em atividades } \\
\text { informais, até profissionais altamente qualificados, oriundos } \\
\text { das mais diferentes partes do país, com múltiplos níveis de } \\
\text { escolaridade, que (re)produzem uma "cultura de migração». } \\
\text { O artigo se baseia em pesquisa bibliográfica e no trabalho de } \\
\text { campo realizado com peruanos no Rio de Janeiro. } \\
\text { Ano XXVI, no 73, jul-dez/2013. São Paulo }\end{array}$ \\
\hline Ano/Edição
\end{tabular}

\section{MULHERES}

Título

A migração de mulheres do ale do Jequitinhonha para São Paulo: de camponesas à proletárias

Autor/es

Maria Aparecida de Moraes Silva

Resumo

O objetivo deste trabalho é apresentar, a partir de dados preliminares de uma pesquisa que estamos desenvolvendo com mulheres migrantes do Vale do Jequitinhonha para a agricultura paulista (região de Ribeirão Preto), algumas reflexões sobre o processo de transformação social que afeta milhares 
de camponeses. Visamos compreender a situação da mulher migrante num conjunto de relações: com a terá, o trabalho, a família, ou seja, buscamos não a análise individualizada desta mulher, o que caberia em ouras situações, mas a análise de uma mulher cuja identidade passa pela propriedade ou posse da terra, de uma mulher camponesa vivenciando o processo de proletarização, em virtude da migração.

Ano/Edição Ano 1, no 1, maio-ago/1988. São Paulo-SP

Título

Constância e permanência: as mulheres de um bairro na periferia de São Paulo

Autor/es

Sylvia Leser de Mello

Resumo

Não é pequena a responsabilidade do pesquisador que se propõe a escrever sobre um bairro popular da periferia de São Paulo, por mais que o conheça há muitos anos. É responsável pela imagem que vai projetar de alguma coisa que conhece, não é a sua experiência pessoal de vida, mas é a vida de outras pessoas. O seu trabalho, portanto, deve ser bastante preciso, deve evitar a excessiva subjetividade, especialmente os preconceitos oriundos de sua classe, tentando, ao mesmo tempo, reconstruir, pela palavra, a riqueza e a variedade constituintes da vida coletiva que está descrevendo. Tomar um bairro como unidade de análise envolve, também, complicações de ordem conceitual: o que é precisamente um bairro? Será dado enfoque especial sobre o papel e a participação das mulheres na organização cotidiana do bairro.

Ano/Edição Ano III, no 7, maio-ago/1990. São Paulo-SP

Título

Autor/es

Resumo

Mulher: sujeito ou objeto do planejamento familiar Angela Arruda

A questão que temos diante de nós é: a mulher consegue controla sua própria fecundidade segundo sua conveniência, ou esta sofre outras pressões e acaba se manifestando sem obedecer aos seus anseios e necessidade?

Ano/Edição Ano IV, no9, jan-abril/1991. São Paulo-SP

Título

Autor/es

Resumo

\section{Operárias na calçada}

\section{Patrick Clarke}

Encontrei, por aí, um dia, as comadres da calçada. Gente nova, povo novo lutador. Semeando a esperança no meio de uma grande desgraça. Vivendo a utopia da vida nova, transformada em poesia do reino, pelas lágrimas amargas da derrota. Parece 
paradoxo. Mas da sarjeta da humilhação, ali em plena cidade nobre, reduto dos poderosos, fortaleza dos que tudo possuem, um "bando de mulheres operárias, sem nada a não ser sua fé e o sonho de um mundo diferente, armou sua tenda e pariu um novo tempo, um mundo que nunca mais vai ser o mesmo. Disso tudo, fui discipulo tardio, testemunha privilegiada, companheiro comovido, solidário. Senti, nas visitas diversas, nas conversas, nas rezas e nas partilhas, a eclosão de algo inédito. De uma boa nova, que o mundo, a nossa sociedade de consumismo exausto, muito precisa.

Ano/Edição Ano VI, no 16, maio-ago/1993. São Paulo-SP

\begin{tabular}{|c|c|}
\hline \multirow{4}{*}{$\begin{array}{l}\text { Título } \\
\text { Autor/es } \\
\text { Resumo } \\
\text { Ano/Edição }\end{array}$} & "De mulher pra mulher" \\
\hline & Dirceu Cutti \\
\hline & Editorial \\
\hline & Ano IX, no26, set-dez/1996. São Paulo-SP \\
\hline \multirow{4}{*}{$\begin{array}{l}\text { Título } \\
\text { Autor/es } \\
\text { Resumo } \\
\text { Ano/Edição }\end{array}$} & Terra vermelha (conto) \\
\hline & Liliana Laganá \\
\hline & Conto \\
\hline & Ano IX, no26, set-dez/1996. São Paulo-SP \\
\hline \multirow{3}{*}{$\begin{array}{l}\text { Título } \\
\text { Autor/es } \\
\text { Resumo }\end{array}$} & O rosto feminino da migração sazonal \\
\hline & Maria Aparecida de Moraes Silva \\
\hline & $\begin{array}{l}\text { Em geral, os estudos sobre as migrações temporárias } \\
\text { revelam que elas se referem aos homens. Segundo estas } \\
\text { interpretações, enquanto as mulheres ficam, os homens } \\
\text { partem. Portanto, se existe visibilidade quanto à migração } \\
\text { masculina, há a invisibilidade quanto à feminina. Este fato } \\
\text { pode ser explicado pelas seguintes razões: I - em se tratando } \\
\text { de populações camponesas, geralmente, o que ocorre, é que } \\
\text { alguém precisa ficar para desempenhar as tarefas agrícolas } \\
\text { durante o tempo de ausência daqueles(as) que partem. } \\
\text { Normalmente, atribuem-se às mulheres o papel de ficarem na } \\
\text { terra, uma vez que o mundo exterior pertence aos homens; } 2 \\
\text { - em virtude das relações de gênero prevalentes na sociedade, } \\
\text { cabe às mulheres as funções ligadas à reprodução, tais como } \\
\text { as tarefas domésticas e o cuidado dos filhos; } 3 \text { - geralmente, } \\
\text { a migração feminina é interpretada vis-a-vis o emprego } \\
\text { doméstico de mulheres solteiras nas cidades. Estes três fatores } \\
\text { fundamentados na compreensão da migração feminina a } \\
\text { partir da óptica da divisão sexual do trabalho, através da qual, }\end{array}$ \\
\hline
\end{tabular}


às mulheres são destinadas as funções reprodutivas acrescidas àquelas ligadas ao trabalho na terra. $\mathrm{O}$ objetivo deste texto é contar uma outra história. História de mulheres migrantes sazonais. Camponesas do Vale do Jequitinhonha (MG) que partem em busca do pão de cada dia na região de Ribeirão Preto (SP). O trabalho é a colheita do café e o corte da cana. Trata-se de mulheres casadas, solteiras, viúvas, sós, com filhos pequenos, maiores, lactentes, grávidas (Silva, 1995).

Ano/Edição Ano IX, no26, set-dez/1996. São Paulo-SP

\begin{tabular}{ll}
\hline Título & A volta por cima \\
Autor/es & Wanderluce Pessoa Bison \\
Resumo & Enfocando o processo migratório sob a perspectiva das \\
implicações decorrentes para os sujeitos nele envolvidos, \\
este artigo aborda um grupo de mulheres que transita entre \\
o Vale do Jequitinhonha-MG e a cidade de São Paulo! Olhar \\
os migrantes sob tal prisma tem conformado uma espécie \\
de lugar central. Os estudos enfatizam, com frequência, as \\
rupturas culturais, as transformações na bagagem política, \\
enfim, os múltiplos impactos que o processo de confronto \\
com universos diversos pode trazer para eles. Partindo desta \\
temática geral, objetivamos pontuar algumas particularidades \\
concernentes ao grupo reportado, chamando a atenção para \\
aspectos que têm sido, até então, pouco explorados pelos \\
pesquisadores. \\
Ano IX, no26, set-dez/1996. São Paulo-SP \\
Ano/Edição
\end{tabular}


últimas décadas, e que seu destino final tenha deixado de ser exclusivamente Buenos Aires, atualmente a emigração de jovens da área rural continua sendo vista como a única opção possível para numerosas famílias.

Ano/Edição Ano IX, no26, set-dez/1996. São Paulo-SP

\begin{tabular}{l|l} 
Título & $\begin{array}{l}\text { Mudança, crise e redefinição de papéis: as mulheres } \\
\text { brasileiras lá fora }\end{array}$ \\
\hline Autor/es & $\begin{array}{l}\text { Sylvia Duarte Dantas De Biaggi } \\
\text { Resumo }\end{array}$
\end{tabular}

Resumo

É sabido que o processo de imigração constitui-se numa difícil experiência de vida, com características únicas. O imigrante tem de lidar com múltiplas perdas decorrentes da mudança de país, em que deixa para trás familiares, amigos, trabalho e todo um contexto onde língua, normas sociais e locais eram bem conhecidos. Além disso, também tem de ajustar-se a um novo local onde oque antes era parte da rotina se torna um desafio diário. Estudiosos definem a adapatação doimigrante aonovo país como um processo de aculturaçao em que ocorre uma mudança na cultura, principalmentedogrupo minoritário, em funçao do contato contínuo entre dois grupos culturais distintos (Berry et al., 1987; Phinney, Chavira, \& Williamson, 1992). Segundo Berry (1980), tal processo envolve três fases:contato, conflito e adaptação. Essa experiência será mais ou menos estressante para o imigrane dependendo de vários fatore, como por exemplo: similaridade ou não na língua, difernçade costumes e valores entre as duas culturas, além de aspectos psicológicos de cada indivíduo.desta forma, oprocesso de aculturaçaõ em sido viso como multivariável, ou seja, muitos fatores entram em jogo na adapatação ao novo local. um destes fatores é a mudança na concepção dos papéis socias de gênero. Este artigo tem como objetiov analsar a experiência das mulheresbrasileiras como imigrantes nos Estados Unidos, particularmente na cidade de Boston, com enfoque em seus papéis de gênero no âmbito da família.

Ano/Edição Ano IX, no26, set-dez/1996. São Paulo-SP

Título Autor/es Resumo

\section{Trabalhadoras brasileiras em Boston}

\section{Ana Cristina Braga Martes}

O objetivo deste artigo é analisar a inserção das mulheres brasileiras no mercado de trabalho na Área Metropolitana de Boston, Estados Unidos, com especial atenção às formas de acesso a este mercado (Margolis, 1992 e 1993; Sales, 1994; 
Soares, 1995). Convém salientar que o número de mulheres brasileiras que atualmente vivem na área é desconhecid0², uma vez que a avassaladora maioria dos brasileiros encontrase na situação de indocumentados. A maioria das brasileiras veio para esta região acompanhada dos maridos, namorados ou pais. Mas há um número cada vez mais significativo de mulheres que emigram sozinhas, sejam elas solteiras, viúvas ou divorciadas. As brasileiras que emigram acompanhadas tendem a ter um papel de menor peso na decisão de migração. Elas influenciam, emitem suas opiniões e ajudam, mas na maioria dos casos, a "decisão final " cabe aos homens. A partir dos dados até agora coletados é possível levantar a hipótese de que o papel da mulher brasileira é mais marcante nas decisões de retorno (De Biaggi, 1993), uma vez que são elas, e não os homens, que mantêm fortalecidos os vínculos afetivos e familiares no Brasil, estimulando a volta de muitas famílias. De qualquer modo, as brasileiras fogem do papel atribuído pelos pesquisadores às mulheres latinas ${ }^{4}$, africanas $e$ asiáticas, cujos comportamentos são descritos como passivos em relação às decisões de migraçã $0^{5}$. Migrar, para as mulheres brasileiras, não tem sido uma experiência vivida para "além do seu controle" como escreve Gina Buijs ao se referir às palestinas e vietnamitas.

Ano/Edição Ano IX, no26, set-dez/1996. São Paulo-SP

\section{Título}

Autor/es

Resumo

Ano/Edição

\section{A mulher migrante em Honduras}

\section{Janete A. Ferreira}

Os países da América Central, durante décadas, foram vítimas de toda sorte de violências políticas e sociais. Foram o palco de guerras civis sangrentas e de massacres indiscriminados, onde a principal vítima foi a população mais pobre. Isso gerou uma onda de refugiados na região, que veio engrossar o caldo dos fluxos migratórios que buscam novas oportunidades nos países da América do Norte. No entanto, uma incipiente industrialização em alguns países, como Honduras, tem provocado uma crescente migração rural-urbana interna. Nas indústrias de Honduras, conhecidas como as maquiladoras, destaca-se a presença de operárias, mulheres migrantes de origem rural. Neste artigo, procura-se traçar um perfil das condições de vida dessa parcela da população trabalhadora hondurenha.

Ano IX, n²6, set-dez/1996. São Paulo-SP 


\begin{tabular}{|c|c|}
\hline \multirow{3}{*}{$\begin{array}{l}\text { Título } \\
\text { Autor/es } \\
\text { Resumo }\end{array}$} & A estrada, a rua e a zona \\
\hline & Nancy Cardoso Pereira \\
\hline & $\begin{array}{l}\text { É Páscoa e alguém da equipe de agentes da Casa começa a } \\
\text { cantar e conversar com as mulheres sobre a vida e as situações } \\
\text { difíceis: os medos e as mortes; as alegrias e surpresas. Fala-se } \\
\text { da frustração que tomou conta dos amigos e amigas de Jesus } \\
\text { quando foi preso e morto sem que ninguém pudesse resistir } \\
\text { ou ajudar. As mulheres falam de seus mortos. São muitos. } \\
\text { Surge um nome de mulher: Maria Madalena. Quem era? O } \\
\text { que se sabe dela? Como deve ter se sentido? Aos poucos, } \\
\text { as mulheres vão dizendo o que ouviram ou aprenderam nas } \\
\text { catequeses e na vida: era prostituta; Jesus a tratou bem: não } \\
\text { foi discriminada; andava com Jesus... Alguém pergunta: de } \\
\text { onde ela era? As mulheres dizem que não sabem. O nome } \\
\text { já diz: Maria de Madalena. Era o nome de uma cidade, uma } \\
\text { região. Maria de Madalena. As mulheres logo entendem. } \\
\text { Claro! Com elas é assim também: recebem o nome do lugar } \\
\text { de onde vieram. Uma é a Gaúcha; a outra é a Mineira...mas } \\
\text { tem também a Mineirinha; duas são Baianas. Os nomes } \\
\text { bem parecidos escondem outros nomes, os verdadeiros que } \\
\text { ninguém ou quase ninguém conhece. } \\
\text { Ano IX, no26, set-dez/1996. São Paulo-SP }\end{array}$ \\
\hline \multirow{3}{*}{$\begin{array}{l}\text { Título } \\
\text { Autor/es } \\
\text { Resumo }\end{array}$} & "Nos trajetos da sujeição" - as brasileiras na Suíça \\
\hline & Luiza Huber \\
\hline & $\begin{array}{l}\text { Quando se toca no assunto da migração de mulheres brasileiras } \\
\text { para a Europa, geralmente este vem associado à prostituição, o } \\
\text { que significa, no mínimo, um desconhecimento de fatores que } \\
\text { têm sua origem na enorme desigualdade sociopolítica entre } \\
\text { os países dos chamados "Primeiro e Terceiro Mundo" e no } \\
\text { interior de muitos países do "Terceiro Mundo' '. A prostituição } \\
\text { no próprio país ou a migração para o "mundo desenvolvido" } \\
\text { são encaradas muitas vezes como sendo as únicas opções para } \\
\text { escapar da miséria. A conquista do coração de um príncipe } \\
\text { encantado em forma de um homem loiro de olhos azuis que } \\
\text { possa garantir um casamento e a estabilidade ainda é o sonho } \\
\text { de um grande número de mulheres brasileiras. Por outro } \\
\text { lado, esse homem encontra na mulher brasileira negra, ou } \\
\text { "cor de jambo" o objeto do seu desejo e de sua fantasia. „Na } \\
\text { Suíça, as brasileiras formam, juntamente com as dominicanas, } \\
\text { marroquinas e tailandesas, o maior grupo de mulheres } \\
\text { migrantes dos chamados países do "Terceiro Mundo' Fica } \\
\text { difícil falar em números exatos, uma vez que grande parte }\end{array}$ \\
\hline
\end{tabular}


delas vive ilegalmente no país e sem registro em nenhum órgão. Em 1995, o FIZ (Centro de Informações para Mulheres da Ásia. África e América Latina, em Zürich), atendeu a 154 mulheres migrantes, dentre as quais 56 eram brasileiras. Elas formam, também no atendimento por telefone, a grande maioria: 52 para um total de 195, Como estas mulheres ingressam na Suiça? Fundamentalmente, são três as formas: como dançarinas, via casamento ou como turistas.

Ano/Edição Ano IX, no26, set-dez/1996. São Paulo-SP

\section{Título}

Autor/es

Resumo

Ano/Edição

Distante do Éden: as condições de trabalho das migrantes na região do São Francisco

\section{Adélia de Melo Branco; Semira Adler Vainsencher}

Analisando-se a realidade concreta do Nordeste do Brasil, de acordo com Bacelar (1997), não há como negar: a despeito do grande crescimento económico e da entrada no mercado globalizado, a pobreza continua sendo uma das características mais marcantes dessa Região. Segundo Guimarães Neto (1997), inúmeros fatores, entre eles a escravidão e a concentração do poder político e econômico, contribuíram para a existência da pobreza que o Nordeste enfrenta, deixaram marcas profundas na economia local e tiveram uma forte influência na sua evolução. Tais fatores concorreram para dificultar o acesso à terra, garantir a presença marcante do latifúndio - onde o proprietário, no contexto de relativo excedente de população, sempre possuiu uma enorme capacidade de definir relações de exploração da força de trabalho - e defender o papel do capital mercantil, no interior da própria economia regional, além do papel que o mesmo exerceu nas relações do Nordeste com os comércios internacional e inter-regional, notadamente na comercialização da produção agrícola.

Ano XIV, no41, set-dez/2001. São Paulo

Título

Autor/es

Resumo

\section{Cooperação e competição entre emigrantes brasileiras}

\section{Soraya Fleischer}

Como já foi amplamente mostrado pela mídia e pela literatura acadêmica, desde a década de 1970, o Brasil tem apresentado um perfil emigracionista e vem se incorporando ao conjunto das nações que abastecem o mercado primeiro-mundista com trabalhadores braçais. Nas últimas décadas do século, ou no chamado "triénio da desilusão" (Sales, 1999, p.32), o desânimo com as políticas económicas, a falta de perspectiva de ascensão social e a desesperança foram os principais motivos 
para a saída dos brasileiros (Assis, 1999, Torresan, 1994, Sasaki, 1999). Assim, a literatura define nossos emigrantes como, prioritariamente, "exilados da crise" ou "refugiados econômicos". É importante inserirmos o caso brasileiro no contexto atual das migrações internacionais (Margolis, 1994). Apesar dos brasileiros se distinguirem do padrão do migrante pobre, pouco instruído e pouco qualificado profissionalmente, também estão na condição de migrantes ilegais ou nãodocumentados e suprem a demanda do mercado secundário e informal. Devido à ilegalidade e ao desconhecimento da língua, eles vão ingressar nos escalões mais baixos da pirâmide de trabalho e constituir uma mão-de-obra subvalorizada, subremunerada e submissa. Os estudos sobre os dekasseguis resumem o perfil destas ocupações com os "3K": kitanai (sujo), kiken (perigoso) e kitsui (penoso) (Sasaki, 1999). Além disso, estes emigrantes se inserem no contexto polêmico e explosivo das medidas restricionistas e xenofóbicas contra estrangeiros.

Ano/Edição Ano XIV, no41, set-dez/2001. São Paulo

Título

Autor/es

Resumo

Ano/Edição

\section{Mulheres imigrantes no Japão}

\section{Lúcia E. Yamamoto}

O presente estudo pretende, através da apresentação dos casos das mulheres que pertencem a essas três maiores comunidades estrangeiras, analisar as funções que elas ocupam na sociedade receptora. Os estudos relacionados à migração feminina são críticos quanto ao pouco caso que se faz da presença feminina no processo migratório. Mesmo os pesquisadores que apontam para a feminização desse processo, dedicam pouca atenção para a sua importância (Kofman, 1999, p.269). Quando são consideradas neste processo, as mulheres são vistas como dependentes de familiares ou então consideradas somente dentro do papel que ocupam na esfera privada (Kofman, 1999, p.270). Neste estudo, vamos tentar demonstrar que, mesmo respondendo às expectativas familiares, as mulheres participam ativamente nesse processo migratório, atuando como força de trabalho dentro da sociedade receptora.

Ano XIV, no41, set-dez/2001. São Paulo

Título

Autor/es

Resumo

\section{Mulheres migrantes na fronteira Brasil-Bolívia}

\section{Roberta Peres Guimarães; Rosana Baeninger}

A migração internacional recente em território brasileiro já se apresenta como um fenómeno relevante, complexo e multifacetado da população há mais de 50 anos, em especial 
nas áreas de fronteiras. Os fluxos migratórios chamam a atenção pela complexidade e volume da circulação de pessoas e capitais, bem como pelos impactos nos espaços migratórios, diversos não somente em pontos de origem e destino, mas também em motivações, trajetórias e estratégias. A fronteira Brasil-Bolívia abriga um movimento intenso entre os dois países, em ondas migratórias de diferentes intensidades (Silva, 1997). Neste contexto, surge o tema da migração feminina e seus diferenciais em todos os aspectos do fenómeno. Baseado numa pesquisa de campo realizada em Corumbá no fim de 2006, em parceria entre o NEPO (Núcleo de Estudos de População) e o IRD (Institut de Recherche pour le Développement) _França, este artigo se propõe a um olhar atencioso sobre as mulheres envolvidas neste fluxo migratório. A perspectiva de género torna-se importante aporte teórico das migrações internacionais, porque revela questões latentes que por muito tempo foram deixadas de lado em função de análise voltada exclusivamente para os aspectos económicos da migração internacional (Morokvasie, 2003; Boyd e Grieco, 2003). O migrante era definido como do sexo masculino, sem que se questionasse a presença das mulheres em fluxos migratórios, e seus diferenciais e impactos causados pelo volume de mulheres que circulavam em espaços migratórios que eram definidos a princípio como masculinos (Morokvasic, 2003). Neste sentido, relações de género construídas desde o lugar de origem dos migrantes e ao longo de todo o processo, delimitam, condicionam, configuram e orientam esses fluxos, através de diferentes vetores, tanto femininos como masculinos, tanto em relações familiares quanto na inserção dos migrantes em seus lugares de destino.

Ano/Edição Ano XXII, no 63, jan-abri/2009. São Paulo

\begin{tabular}{ll} 
Título & Tráfico de mulheres: um novo/velho drama amazônico \\
\hline Autor/es & Lúcia Isabel da Conceição Silva; Marcel Theodoor Hazeu \\
Resumo & Este artigo aborda o tráfico de mulheres da Amazônia para \\
o Suriname, baseado na pesquisa Trinacional sobre Tráfico \\
de Mulheres do Brasil e da República Dominicana para o \\
Suriname, realizada entre 2007 e 2008 sob a coordenação da \\
ONG Sociedade dos Direitos Sexuais Amazônia-SODIREITOS. O \\
estudo ouviu 15 mulheres brasileiras e 8 mulheres dominicanas \\
que vivenciaram a situação de tráfico em clubes no Suriname. \\
Neste texto discutem-se as situações de violações vivenciadas \\
por essas mulheres antes e durante a situação de tráfico.
\end{tabular}


Uma das conclusões do estudo é a percepção da relação entre a situação das mulheres e o contexto das relações de gênero na Amazônia, assim como resultantes das políticas de desenvolvimento implementadas na região.

\begin{tabular}{ll} 
Ano/Edição & Ano XXV, no 71, jul-dez/2012. São Paulo \\
\hline Título & $\begin{array}{l}\text { Apresentação - A importância da categoria "gênero" nos } \\
\text { novos estudos migratórios }\end{array}$ \\
\hline Autor/es & $\begin{array}{l}\text { Ana Carolina Gonçalves Leite } \\
\text { Resumo }\end{array}$ \\
Ano/Edição & $\begin{array}{l}\text { Ano XXIX, no 78, jan-jun/2016. São Paulo } \\
\text { Ano }\end{array}$
\end{tabular}

Título

A face feminina na migração "permanentemente" temporária no estado de São Paulo: o caso das trabalhadoras da citricultura

Autor/es

Resumo

Lidiane M. Maciel; Giovana Gonçalves Pereira

Ano/Edição

Este artigo tem como objetivo apresentar a face feminina nos processos migratórios "permanentemente" temporários (SILVA, 1992) na Região Administrativa Central do Estado de São Paulo nos anos recentes. A abordagem metodológica fundamentou-se na aplicação de técnicas qualitativas que privilegiaram entrevistas semiestruturadas e biografias migratórias com familiares de trabalhadores rurais do setor citrícola da referida região. Para tanto, foram realizadas pesquisas de campo nos municípios de São Carlos e Matão no interior paulista e Jaicós no interior piauiense. Nossa hipótese central é de que os processos migratórios alteram profundamente a posição das mulheres em relação às suas famílias e em suas comunidades de origem, lançando-as num jogo de recomposição de suas identidades sociais.

\begin{tabular}{ll} 
Ano/Edição & Ano XXIX, n- 78, jan-jun/2016. São Paulo \\
\hline Título & $\begin{array}{l}\text { Rostos femininos nas migrações internacionais: mulheres } \\
\text { brasileiras no Sul da Flórida }\end{array}$ \\
\hline Autor/es & $\begin{array}{l}\text { Valéria Barbosa Magalhães; José Renato de Campos Araujo } \\
\text { Resumo }\end{array}$ \\
$\begin{array}{l}\text { Este artigo busca chamar a atenção para a heterogeneidade } \\
\text { que caracteriza a diáspora brasileira para o exterior. Parte- } \\
\text { se da constatação de que os estudos migratórios brasileiros } \\
\text { tendem tradicionalmente a não perceber a diversidade e } \\
\text { as várias dimensões do fenômeno migratório como partes } \\
\text { constitutivas de nossa presença nos quatro cantos do mundo. } \\
\text { O artigo toma como exemplo as mulheres brasileiras no Sul } \\
\text { da Flórida e está baseado em intensa pesquisa de campo } \\
\text { realizada entre } 2002 \text { e 2015, assentada em fontes diversas e }\end{array}$
\end{tabular}


em métodos qualitativos combinados. Buscou-se mostrar que as experiências migratórias de mulheres indicam que vivências subjetivas dificilmente podem ser generalizadas, mas que constituem e explicam quadros coletivos mais amplos. Este fato complica qualquer expectativa de interpretações estruturais únicas para as migrações.

Ano/Edição Ano XXIX, no 78, jan-jun/2016. São Paulo

Título

Autor/es

Resumo

Ano/Edição

Título

Autor/es

Resumo

Ano/Edição

Título

Autor/es

Resumo

\section{Rostos goianos na migração}

\section{Juliana dos Santos Pereira Moraes}

Neste artigo descrevo algumas trajetórias que representam percursos migratórios das imigrantes goianas, que moram em Lisboa. Por meio delas é possível pensar sobre algumas articulações e interseccionalidades que são feitas a partir de marcadores sociais como ser mulher e brasileira num contexto migratório e de que modo esses marcadores ainda se articulam com a categoria regional.

Ano XXIX, no 78, jan-jun/2016. São Paulo

Mulheres em movimento: registrando memórias migrantes

Tatiana Chang Waldman; Maria Angélica Beghini Morales

A proposta deste artigo é apresentar o Projeto de História Oral do Museu da Imigração intitulado "Mulheres em movimento: migração e mobilização feminina no estado de São Paulo", que teve início em julho de 2015. Desde então já foram realizadas entrevistas com oito mulheres migrantes, todas residentes na cidade de São Paulo, de diferentes idades, origens (até o momento entrevistamos mulheres de países da América do Sul, como Bolívia, Chile e Peru), e com trabalhos e projetos em diversas áreas de atuação. $O$ projeto foi elaborado a partir da observação de uma crescente mobilização e conquista de espaços, especialmente nos últimos anos, por parte das mulheres migrantes na cidade de São Paulo. A proposta é refletir sobre o processo migratório e a experiência da mobilidade da perspectiva feminina e de gênero. Ano XXIX, no 78, jan-jun/2016. São Paulo

Vivencias discriminatorias según colombianas e paraguayas radicadas en Ecuador y Brasil

\section{Elizabeth Ruano; Patrícia Nabuco Martuscelli}

A partir de las respuestas de migrantes colombianas y paraguayas radicadas en Ecuador y Brasil respectivamente $y$, en perspectiva con las disposiciones de los tratados 
internacionales, se objetiva analizar la yuxtaposición de formas de discriminación negativa, género, nacionalidad, lingüística, étnico-racial y estatus migratorio. La intersección analítica entre esas afirmativas y los dispositivos internacionales contra la discriminación, de los cuales son signatarios los cuatro países aquí analizados, ratifica la distancia entre los postulados de esas normativas internacionales y la situaciones cotidianas de discriminación que obstaculizan la inserción digna de las inmigrantes en los países de destino.

Ano/Edição Ano XXIX, no 78, jan-jun/2016. São Paulo

Título

Autor/es

Resumo

Ano/Edição

Título

Autor/es

Resumo
A feminização como tendência da migração boliviana para São Paulo

\section{Clara Lemme Ribeiro}

O presente artigo pergunta-se sobre a nova tendência migratória chamada de feminização das migrações, partindo do caso empírico do fluxo de bolivianos para São Paulo. A presença feminina boliviana passa a chamar atenção após a década de 1990, quando começa a aumentar rapidamente. Os motivos de saída da Bolívia das mulheres relacionam-se às dificuldades no acesso à terra, ao trabalho e ao dinheiro. Após a chegada, as trajetórias passam necessariamente pelo emprego na costura, podendo seguir por outros caminhos. Nas oficinas, as mulheres lidam com uma divisão do trabalho produtivo, a realização das atividades domésticas, o cuidado com os filhos e a exposição à violência sexual. Em nossa interpretação, a feminização das migrações constitui-se como um momento da crise do trabalho, tanto em relação à sua mobilização para fora do país de origem quanto em relação à sua inserção. $O$ cerne dessa nova tendência é a contradição entre um ganho de autonomia por parte das mulheres e uma exposição a formas renovadas de violência.

Ano XXIX, no 78, jan-jun/2016. São Paulo

Mulheres japonesas e suas famílias: migração e colonização privada no estado de Mato Grosso - 1952

\section{Aldina Cássia Fernandes da Silva}

Este texto tem como proposta compreender a relação entre a formação de sentido cultural e o papel das mulheres japonesas e suas famílias na colônia Gleba Rio Ferro, no estado de Mato Grosso - MT. Essas mulheres são filhas de imigrantes japoneses que vieram para o Brasil antes da Segunda Guerra Mundial e permaneceram nas cidades de Marília - SP e Assaí 
- PR até 1952, momento em que as famílias adquiriram lotes de terras no projeto de colonização privada conduzido pela Colonizadora Rio Ferro Ltda., no estado de Mato Grosso. Para tanto, a história oral será utilizada como metodologia na interpretação das experiências vivenciadas durante o processo migratório e na nova área de ocupação dessas famílias.

Ano/Edição Ano XXIX, no 78, jan-jun/2016. São Paulo

$\begin{array}{ll}\text { Título } & \text { Vozes de mulheres migrantes não apenas em } 8 \text { de março } \\ \text { Autor/es } & \begin{array}{l}\text { Elizabeth Ruano } \\ \text { Resumo }\end{array} \\ & \begin{array}{l}\text { Neste relato problematizo o caráter trivial que pode assumir a } \\ \text { noção de representação em contextos migratórios. Para tanto, } \\ \text { retomo a minha participação em condição de representante } \\ \text { das mulheres migrantes na mesa1 de abertura do "Seminário } \\ \text { Regional de Cooperação Sul-Sul sobre a Proteção dos Direitos } \\ \text { dos Trabalhadores e Trabalhadoras Migrantes na América } \\ \text { Latina e no Caribe"2, realizado em } 83 \text { de março de } 2016 . \\ \text { Essa incursão esteve demarcada pela comemoração do dia } \\ \text { internacional da mulher e se tratou de uma homenagem }\end{array} \\ \text { idealizada pela organização desse evento às mulheres } \\ \text { migrantes. Atualmente alcançam mais de } 111 \text { milhões de } \\ \text { mulheres, número que representa 48\% do contingente global } \\ \text { de migrantes no mundo. } \\ \text { Ano XXIX, no 78, jan-jun/2016. São Paulo }\end{array}$

\section{NOMADISMOS}

Título

Autor/es

Resumo

Ano/Edição

Título

Autor/es

Resumo

Ano/Edição
Nomadismos: dos pastos ao asfalto

\section{Heinz Dieter Heidemann}

Editorial

Ano X, no 27, jan-abril/1997. São Paulo

Eu poderia fugir com eles ( Depoimento )

Paulo Pedro Garcia, por Dirceu Cutti

Depoimento

Ano X, no 27, jan-abril/1997. São Paulo-SP

\section{Título}

Autor/es

Resumo

\section{Ciganos}

\section{Mirella Karpati}

Quem é o cigano? O que é que faz do cigano um cigano? Uma história comum, uma língua comum- tradições e costumes comuns? Todos esses fatores, que são elementos fundantes de 